\title{
The effect of milk production level on host resistance of dairy cows, as assessed by the severity of experimental Escherichia coli mastitis
}

\author{
Esther KORNALIJNSLIJPER ${ }^{\mathrm{a} *}$, Bonne BEERDA ${ }^{\mathrm{b}}$, Ineke DAEMEN ${ }^{\mathrm{a}}$, \\ Joop VAN DER WERF ${ }^{\mathrm{b}}$, Tine VAN WERVEN ${ }^{\mathrm{a}}$, Theo NIEWOLD ${ }^{\mathrm{b}}$, \\ Victor RUTTEN $^{\mathrm{c}}$, Elsbeth NOORDHUIZEN-STASSEN ${ }^{\mathrm{a}}$ \\ ${ }^{a}$ Department of Farm Animal Health, Ruminant Health Unit, Faculty of Veterinary Medicine, \\ Utrecht University, Yalelaan 7, 3584 CL Utrecht, The Netherlands \\ b Division of Animal Sciences, Institute for Animal Science and Health, PO Box 65, \\ 8200 AB Lelystad, The Netherlands \\ ${ }^{c}$ Immunology Division, Department of Infectious Diseases and Immunology, Faculty of Veterinary \\ Medicine, Utrecht University, Yalelaan 1, 3584 CL Utrecht, The Netherlands
}

(Received 23 December 2002, accepted 14 April 2003)

\begin{abstract}
This study investigated the possible effects of milk production level on the host resistance of dairy cows. High $(n=18)$ and low $(n=18)$ producing cows on a research farm, which respectively produced 11443 and $7727 \mathrm{~kg}$ milk in their previous lactation, were compared. To enhance the possible differences in host resistance between high and low producing cows, the animals in both groups were metabolically stressed by overfeeding during the dry period or were fed according to requirements, resulting in four groups of nine cows. The metabolic status was monitored from two weeks pre-partum until 2.5-4.5 weeks post-partum. Host resistance was assessed by measuring the severity of experimentally induced Escherichia coli mastitis. Pre-partum blood glucose levels tended to be higher in overfed cows than in cows fed according to requirements. The post-partum energy balance was significantly more negative in high producing cows than in low producers, and tended to be more negative in overfed cows compared to cows fed according to the requirements. Post-partum plasma glucose, NEFA, $\beta-\mathrm{OH}$-butyrate and urea concentrations were similar in the four groups. Plasma glucose concentrations were significantly lower and liver triacylglycerol concentrations were significantly higher in third than in second parity cows. Host resistance was not affected by the production level or feeding regimen. There were no significant correlations between the metabolic status and the severity of experimental $E$. coli mastitis, except for the relatively more severe mastitis in the cows with $\beta$-OH-butyrate concentrations above $1.4 \mathrm{mmol} / \mathrm{L}$. In conclusion, milk production level did not affect host resistance in dairy cows, as measured by the severity of experimental E. coli mastitis. Even in a situation where cows were metabolically stressed by overfeeding, high producers were as able as low producers to cope with the demands of milk production, without consequences for host resistance.
\end{abstract}

dairy cow / milk production / host resistance / metabolism / E. coli mastitis

\footnotetext{
* Corresponding author: j.e.kornalijnslijper@vet.uu.nl
} 


\section{INTRODUCTION}

Milk production, one of the most important factors contributing to the profitability of a dairy farm, has tremendously increased during the past decades in Western Europe and North America. In the Netherlands, the mean milk production level of dairy cows increased from around $5000 \mathrm{~kg}$ in 1970 to $8000 \mathrm{~kg}$ in 2000 [16]. It is a growing concern that these high milk production levels are realised at the expense of the dairy cows' health and well-being. Whether or not high milk production is associated with poor health has mainly been investigated in epidemiological studies. For example, studies from the northeast USA and recently Germany suggest an increased risk of clinical mastitis with increasing milk production [6-8]. However, epidemiological studies are generally not conclusive in terms of causal relations between observed risk factors and disease [21]. To substantiate the hypothesis that increasingly higher milk production negatively affects the dairy cows' health, experimental studies are necessary. Such studies could also add to the understanding of underlying mechanisms, which are likely to involve host resistance and metabolic status.

Detilleux et al. [4] compared host resistance between high and low producing cows, but did not find negative effects of milk production level on in vitro neutrophil functions and antibody production. However, these host resistance parameters have been measured in a "steady state" situation, and therefore do not give information on the animals' capacity to respond when challenged. A method to achieve this is to measure induced in vivo humoral and cellular responses after immunisations with a test-antigen such as tetanus-toxoid [27]. Unfortunately, it is not clear to what extent responsiveness to immunisations with testantigens is related to resistance to infectious diseases. The latter is most reliably assessed when using disease models. A useful disease model is that of Escherichia coli mastitis, a relevant problem in dairy herds $[1,5]$. The severity of experimental E. coli mastitis may be used as a parameter of host resistance in dairy cows. The effects of high milk production on host resistance could be mediated by the metabolic status of the animal. The metabolic status reflects the way cows cope with the demands of milk production, e.g. by means of utilizing body fat, and to what extent they manage, e.g. blood levels of ketones and glucose. Ketosis, a situation where coping has been inadequate, has been associated with an increased risk of clinical mastitis in the field $[8,17]$. These epidemiological findings have been substantiated by experimental in vivo and in vitro data $[13,22]$. It could therefore be of interest, in an experimental setting, to enhance the possible differences in host resistance between high and low producing cows by challenging their metabolism. A well known metabolic stressor, which frequently occurs in the field, is overfeeding during the dry period. This may lead to overcondition at calving and to depression of appetite after calving. As a consequence, cows may go into a more severe negative energy balance post-partum (review by [20]).

The aim of this study was to investigate the possible effects of milk production level on the host resistance of dairy cows, assessed by measuring the severity of experimentally induced $E$. coli mastitis, in situations where cows were either or not metabolically stressed.

\section{MATERIALS AND METHODS}

\subsection{Experimental design}

The main factors in the experiment were milk production level and feeding regimen during the dry period. Two milk production levels were used ("high production" (HP) versus "low production" (LP); see Sect. 2.2). During the dry period the cows were either fed according to recommendations for energy requirements $($ control $=\mathrm{c})$ or fed 
approximately twice such recommendations (overfed $=0$ ), and this resulted in four experimental groups: HP-c, LP-c, HP-o and LP-o (for nutrition: see Sect. 2.3). Within the production groups, the cows were alternately assigned to a feeding regimen in order of expected calving date, until a total of 9 cows per group was achieved. Host resistance was assessed by quantifying the severity of experimental E. coli mastitis. The cows were in week $2.5-4.5$ post-partum at the moment of intramammary infusion with approximately $50 \mathrm{cfu} E$. coli (see Sect. 2.5). The cows that calved within a period of two weeks were tested as a group and this resulted in 11 test groups of 1 6 animals. The experiment was approved by the Animal Care and Ethics Committee of the Institute for Animal Science and Health, Lelystad, the Netherlands.

\subsection{Animals and housing}

A total of 39 animals, including $27 \mathrm{sec}-$ ond and 12 third parity cows, of the research farm of the Institute for Animal Science and Health, Lelystad, the Netherlands, were entered in this study. Cows were 100\% Holstein Friesian (HF), except for three crossbreds $(\geq 50 \% \mathrm{HF})$. The herd size of the farm was approximately 400 dairy cows. The animals were selected and categorized based on 305 days fat and protein corrected milk production (FPCM) in the previous lactation. The selection criteria were related to the mean production level of the farm (approximately $9500 \mathrm{~kg}$ ). The cows in the "high producing (HP) group" and "low producing (LP) group" had mean FPCM ( \pm s.d.) in their previous lactation of $11443 \pm 838 \mathrm{~kg}$ (ranging from 9999 to $13364 \mathrm{~kg}$ ) and $7727 \pm 640 \mathrm{~kg}$ (ranging from 6596 to $8686 \mathrm{~kg}$ ), respectively. The animals calved during the period from October 2000 through April 2001. The animals were housed in a free stall with cubicles during the dry period and were moved to a calving pen shortly before the expected calving. After calving, the cows were moved to a tie stall. The cows were milked twice daily in a rotating milking parlor with milking intervals of 10 and 14 hours. Diseased animals were treated following the standard procedures of the research farm.

\subsection{Nutrition}

During the dry period the cows were fed a Total Mixed ration (TMR; see Tab. I). The food was provided to them as a group in the free stall. During the dry period the HP-c and LP-c cows were fed around $60 \mathrm{MJ}$ per day (dry period TMR-c). The HP-o and LP-o cows were fed around $120 \mathrm{MJ}$ per day (dry period TMR-o). Initially, the cows were fed TMR I. This TMR was adapted by the manager of the research farm into TMR II to improve mineral supplementation in order to prevent impending milk fever problems in the herd. As a consequence, one third of the animals received TMR I only, part TMR I / part TMR II and TMR II only, respectively. All animals received TMR-o from ten days before the expected calving. Postpartum, all animals were individually fed ad libitum lactation TMR in the tie stall. Here, daily feed intakes of the individual cows were registered.

\subsection{Metabolic parameters}

Milk production was recorded twice daily. Composite milk sampling for milk fat and protein percentages was performed during four consecutive milkings per week (Tuesday afternoon until Thursday morning). Bodyweights were recorded twice daily after calving. A liver biopsy for liver triacylglycerol (TAG) determination was taken as described before [24], when the cows were between 6-13 days after calving. Blood sampling for the measurement of glucose, non-esterified fatty acids (NEFA), $\beta$-OH-butyrate (BHB) and urea started three weeks before the expected calving dates. Blood was sampled twice a week (Mondays and Thursdays) from the tail vein using $10 \mathrm{~mL}$ evacuated tubes containing 
Table I. Compositions of the Total Mixed Rations (TMR).

\begin{tabular}{|c|c|c|c|c|c|}
\hline & \multicolumn{2}{|c|}{$\begin{array}{c}\text { Dry period } \\
\text { TMR I (until Dec. 2000) }\end{array}$} & \multicolumn{2}{|c|}{$\begin{array}{c}\text { Dry period } \\
\text { TMR II (from Dec. 2000) }\end{array}$} & \multirow[t]{2}{*}{$\begin{array}{l}\text { Lactation } \\
\text { TMR }\end{array}$} \\
\hline & TMR I-c & TMR I-o & TMR II-c & TMR II-o & \\
\hline $\begin{array}{l}\text { Percentage of: } \\
\text { wheat straw }\end{array}$ & 24 & & 23 & & \\
\hline grass silage & 12 & 21 & 37 & 35 & 17 \\
\hline maize silage & 55 & 43 & 26 & 38 & 36 \\
\hline soja beans, extracted & 9 & 6 & 11 & 12 & 6 \\
\hline dried grass & & 11 & & 8 & 9 \\
\hline concentrates & & 19 & & & 32 \\
\hline grass seed straw & & & & 3.5 & \\
\hline Mervit dEV mix & & & 2 & 3 & \\
\hline Mervit droogstand & & & 1 & 0.5 & \\
\hline TMR (kg/day) & 21.3 & 37.6 & 25.2 & 43 & 45.4 \\
\hline DM (kg/day) & 10 & 18.6 & 11.8 & 18.8 & 22.4 \\
\hline $\mathrm{NE}_{1}(\mathrm{MJ})$ & 59.9 & 128.4 & 65.6 & 118.4 & 155.1 \\
\hline DVE (g/day) & 599 & 1816 & 828 & 1601 & 2314 \\
\hline OEB (g/day) & -2 & 128 & 351 & 610 & 307 \\
\hline
\end{tabular}

Abbreviations: $\mathrm{TMR}=$ total mixed ration, $-\mathrm{c}=$ cows fed according to requirements, $-\mathrm{o}=$ overfed cows, $\mathrm{DM}=$ dry matter, $\mathrm{NE}_{1}=$ net energy for lactation, $\mathrm{DVE}=$ true protein digested in the small intestine, and $\mathrm{OEB}=$ degraded protein balance (for the latter two items, see [23]).

EDTA (Vacuette ${ }^{\circledR}$, Greiner B.V., the Netherlands). Blood sampling continued until experimental E. coli mastitis (Wednesdays), with an extra sample taken just prior to infusion. Blood samples were centrifuged for $12 \mathrm{~min}$ at $1600 \times \mathrm{g}$ at $4{ }^{\circ} \mathrm{C}$ and stored at $-20^{\circ} \mathrm{C}$ until assayed.

\subsection{Induction of $\boldsymbol{E}$. coli mastitis}

The cows were between 18 and 31 days post-partum at the moment of experimentally induced $E$. coli mastitis. An encapsulated strain of E. coli $\mathrm{O} 157$ (non-verotoxic), isolated from a cow with clinical mastitis, was used for intramammary infusion [14]. The strain was subcultured in brain-heart infusion broth CM 225 (Oxoid; Hampshire, England) at $37{ }^{\circ} \mathrm{C}$ starting 2 days before each intramammary infusion. After 22 hours of incubation, the bacterial culture was washed three times in pyrogen-free saline.
Subsequently bacterial counts were determined by dilution plating of serial dilutions using a spiral plater (Lameris Laboratory, Breukelen, the Netherlands) and violet red bile glucose agar CM484 plates (Oxoid, Hampshire, England). The bacterial suspension was refrigerated $\left(4{ }^{\circ} \mathrm{C}\right)$ until the next day. Shortly before intramammary infusion, the culture was diluted in pyrogen-free saline to a concentration of approximately $10 \mathrm{cfu} / \mathrm{mL}$. At three time-points pre-infusion (6 days, 2 days and just prior to intramammary infusion), quarter milk samples were taken for bacteriology and SCC. One of the rear quarters free of major pathogens and with SCC $<150000$ cells/mL was used for experimental infusion. Five millilitres of E. coli suspension containing approximately $50 \mathrm{cfu}$ was infused aseptically. The actual counts of the inocula were determined by dilution plating, and ranged from 30 to $50 \mathrm{cfu}$. 
Before and after experimental infusion the following parameters were recorded: body temperature, general impression, quarter symmetry and firmness (pre-infusion, hourly up to 24 hours after infusion, thereafter at 30, 36, 42, 48, 60, 72 and 96 hours after infusion), bacterial counts in milk, and milk color and aspect (pre-infusion, every 3 hours until 24 hours after infusion, at 30, 36, 42, 48, 60, 72 and 96 hours after infusion and thereafter every 24 hours until negative, i.e. $<1 \mathrm{cfu} / \mathrm{mL}$ ). Before each milk sampling, the teat ends were swabbed with cotton swabs drenched in methylated spirits and the first few streaks of milk were discarded. After E. coli infusion, the bacterial counts in the milk were determined using a spiral plater (Lameris) on violet red bile glucose agar CM 484 (Oxoid). In addition, per sample, bacterial counts in $1 \mathrm{~mL}$ milk were determined using a pour-plate technique, so that the detection limit in this experiment was $1 \mathrm{cfu} / \mathrm{mL}$. Quarter milk production was measured from six milkings before until six milkings after experimental infusion of $E$. coli using a quarter milking machine in the tie stall. The milking interval after experimental infusion was 12 hours.

The severity of experimental E. coli mastitis was expressed as: ${ }^{10} \log$ peak bacterial counts in milk, area under the curve (AUC) of bacterial counts in milk in time [14], bacterial clearance time (BCT) and residual milk production (RMP; [26]). AUC $\left({ }^{10} \log \mathrm{cfu} \times \mathrm{h}\right)$ was calculated using the following equation:

$$
\begin{aligned}
\mathrm{AUC}= & \sum\left\{\left(\mathrm{t}_{\mathrm{i}}-\mathrm{t}_{\mathrm{i}-1}\right) \mathrm{f}_{\mathrm{i}-1}\right\}+\left\{0.5\left(\mathrm{t}_{\mathrm{i}}-\mathrm{t}_{\mathrm{i}-1}\right)\right. \\
& \left.\left(\mathrm{f}_{\mathrm{i}}-\mathrm{f}_{\mathrm{i}-1}\right)\right\},
\end{aligned}
$$

where: $\mathrm{t}_{\mathrm{i}}=$ time of observation, $\mathrm{t}_{\mathrm{i}-1}=$ previous time of observation, $f_{i}={ }^{10} \log$ bacterial counts at time $\mathrm{i}, \mathrm{f}_{\mathrm{i}-1}={ }^{10} \log$ bacterial counts at time $\mathrm{i}-1$.

BCT was defined as the interval between intramammary infusion and the time-point that bacterial counts are below the detection limit $(<1 \mathrm{cfu} / \mathrm{mL})$. RMP was calculated using the mean quarter milk production of the three non-infused quarters during the six pre-infusion milkings as the baseline. The milk production of the non-infused quarters on the second day after infusion (mean of the milking 36 and 48 hours after infusion), was expressed as a percentage of the baseline.

\subsection{Calculation of the energy balance}

The energy balance (EB), expressed as daily mean per week in lactation, was calculated as the difference between the energy intake and energy requirements for maintenance and milk production, using the following equations:

$\mathrm{EB}=$ energy intake - energy requirements with: energy intake $=\mathrm{NE}_{1}$ intake $/$ day $=\mathrm{kg}$ $\mathrm{DMI} /$ day $* \mathrm{NE}_{1} \mathrm{TMR}$, energy requirements $=\left(42.4 * \mathrm{BW}^{0.75}+442 * \mathrm{FPCM}\right) *$ $[1+($ FPCM -15$) * 0.00165]$, where: $\mathrm{kg}$ $\mathrm{DMI} /$ day $=\mathrm{kg}$ feed intake/day $*$ dry matter $(\mathrm{g} / \mathrm{kg}) * 0.001, \mathrm{FPCM}=(0.337+0.116 *$ fat content $+0.06 *$ protein content $) * \mathrm{~kg}$ milk/milking and: $\mathrm{NE}_{1}=$ net energy for lactation $(\mathrm{MJ}), \mathrm{DMI}=$ dry matter intake (average per week), TMR = total mixed ration, $\mathrm{BW}=$ body weight (average per week), FPCM = fat and protein corrected milk production (four milkings per week).

\subsection{Assay procedures}

Plasma glucose (Hexokinase method; Gluco-quant ${ }^{\circledR}$; Roche Diagnostics GmbH, Mannheim, Germany), NEFA (ACSACOD enzymatic colometric method; Wako NEFA C test, Wako Chemicals USA Inc. Richmond USA), BHB (Hydroxybutyrate-dehydrogenase method; Roche Diagnostics $\mathrm{GmbH}$ ) and urea (GLDH method; UR225, Randox Laboratories Ltd., Crumlin UK) were measured enzymatically with commercially available kits. TAG concentration in liver tissue was determined using a commercial kit (kit number 337-A; Sigma Chemical Co.; St. Louis, MO, USA). Bacteriological culture was performed to check the sterility of preinfusion milk samples, according to the 
standard of the National Mastitis Council [9]. Six millilitres of composite milk samples and pre-infusion quarter milk samples were transferred to glass tubes containing Na-azide and were assayed for SCC (Fossomatic, Foss Electric, Hillerød, Denmark) and percentages of fat, protein and lactose (Milcoscan, Foss Electric, Hillerød, Denmark).

\subsection{Statistical analysis}

All statistical procedures were performed using SPSS 8.0 for Windows (SPSS Inc., Chicago, Illinois, USA). The normality of the data was checked by examination of normal probability plots of unstandardized residuals. If necessary, data were ${ }^{10} \log$ transformed. The following models (1 to 4 ) were used:

(1) A general linear model (general factorial) was used with the production level and feeding regimen (including interactions) as fixed factors. The dependent variables in this model were respectively prepartum blood metabolite concentrations (glucose, NEFA, BHB, urea), ${ }^{10} \log$ TAG, ${ }^{10} \log$ peak cfu, ${ }^{10} \log$ AUC, ${ }^{10} \log$ BCT or RMP. Pre-partum blood metabolite concentrations were calculated as the mean of the concentrations in the samples taken in the 14 days pre-partum. Possible influences of milk production level on the severity of E. coli mastitis $\left({ }^{10} \log\right.$ peak cfu, ${ }^{10} \mathrm{log}$ AUC, ${ }^{10} \log$ BCT or RMP) were also analyzed by inclusion of the animals' previous lactation FPCM or mean milk production in the pre-infusion week as a covariate.

(2) A general linear model for repeated measures was used with the production level and feeding regimen (including interactions) as between-subject factors. Within subject variables (time) were respectively FPCM in weeks 2 and 3, EB in weeks 2 and 3 , and post-partum blood glucose, NEFA, BHB and urea concentrations in weeks 1, 2 and 3. Periparturient changes in blood metabolite concentrations were analyzed us- ing repeated measures as well (within subject variables: week -1 and week 1 ).

For both models (1) and (2), the possible effects of parity were controlled by means of including parity as a covariate ( second parity $=0$, third parity $=1$ ). Interactions (production level $\times$ feeding regimen) and covariates with $P$-values $>0.05$ were left out of the model.

(3) Partial correlation coefficients, which control the differences between groups, were calculated in order to investigate the associations between pre-infusion metabolic status and the severity of E. coli mastitis. Pre-infusion metabolic status was defined as the mean of values of EB and blood glucose, NEFA, BHB or urea in the week prior to $E$. coli infusion. For blood metabolite values this was the mean of three samples taken in the week prior to infusion (Thursday, Monday and Wednesday). Partial correlation coefficients were also calculated for associations between ${ }^{10} \log$ TAG and the severity of $E$. coli mastitis.

(4) The possible influences of metabolic status on the severity of $E$. coli mastitis were also analyzed by inclusion of all preinfusion metabolic parameters in a general linear model (general factorial) as covariates.

For all models, the level of significance was set at $P<0.05$.

\section{RESULTS}

\subsection{Cows and milk production}

During the experiment two cows were excluded from the study. One of these had a non-functional quarter and the other had both rear quarters with SCC > 150000 cells $/ \mathrm{mL}$, and Staphylococcus aureus was isolated from the left rear quarter. A third cow was treated with antibiotics for acute claw disorders at the time of the HPA tests, and excluded from these tests. This animal was included for experimental 


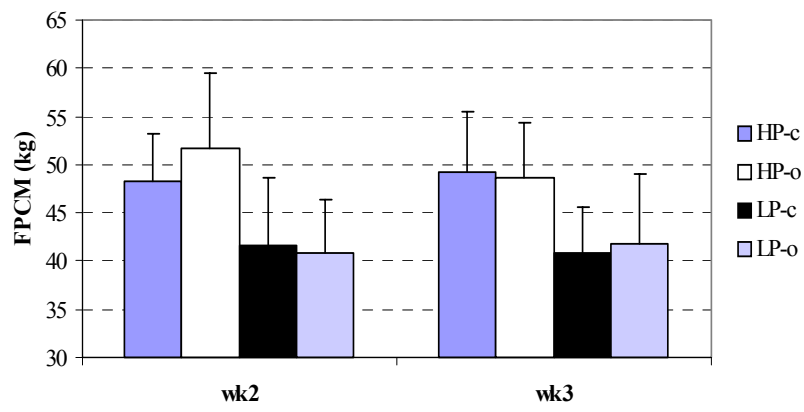

Figure 1. Mean FPCM ( \pm s.d.) in weeks 2 and 3 after calving. HP $=$ high producing, LP $=$ low producing, $-\mathrm{c}=$ fed according to requirements during the dry period, $-\mathrm{o}=$ overfed during the dry period.

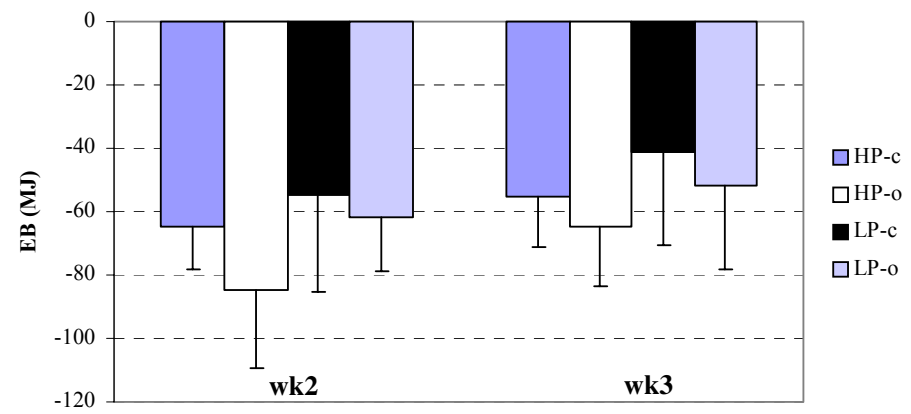

Figure 2. Mean ( \pm s.d.) calculated Energy Balance $(E B)$ in weeks 2 and 3 after calving. $\mathrm{HP}=$ high producing, $\mathrm{LP}=$ low producing, $-\mathrm{c}=$ fed according to requirements during the dry period, $-\mathrm{o}=$ overfed during the dry period.

E. coli mastitis, and an additional animal was used to complete the $4 \times 9$ animals for the HPA measurements. Therefore, data on metabolic status are available for 37 cows. Eight cows were treated with antibiotics in the early post-partum period: five cows (1 HP-o, 1 LP-c, and 3 LP-o) for retentio secundinarum and/or endometritis, one of which received additional treatment for ketonuria (LP-o), two cows (1 HP-o and $1 \mathrm{LP}-\mathrm{o})$ for claw disorders and one cow (HP-c) for clinical mastitis in the right front quarter. Three cows (2 HP-c and 1 LP-c) received milk fever treatment. Mean FPCM ( \pm s.d.) in weeks 2 and 3 post-partum are presented in Figure 1. FPCM was significantly higher in HP cows than in LP cows $(P<0.001)$.

\subsection{Metabolic status}

\subsubsection{Energy balance}

Mean energy balance ( \pm s.d.) in weeks 2 and 3 post-partum are presented in Figure 2. For all cows, EB was negative during the observation period. In all groups, EB became significantly less negative in week 3 compared to week $2(P<0.01)$. EB was significantly affected by production level $(P=0.026)$, with more negative EB in high producing cows. EB tended to be affected by the feeding regimen $(P=0.085)$, with more negative EB in overfed cows. Four cows (2 LP-c and 2 LP-o) were excluded from the repeated measures analysis due to missing body weights in week 3 . The results 


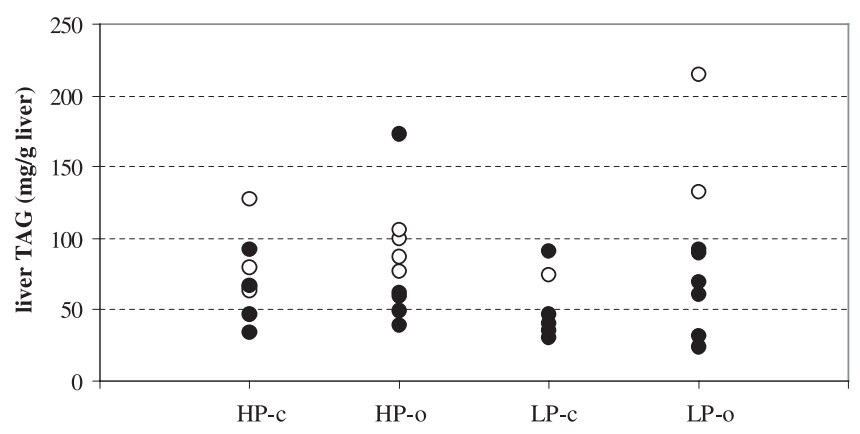

Figure 3. Scatter plot of individual liver TAG content (mg/g liver) in liver biopsies taken between 6 and 13 days after calving (HP-c: $n=8$; HP-o: $n=9$; LP-c: $n=6$; LP-o: $n=8$ ). HP = high producing, $\mathrm{LP}=$ low producing, $-\mathrm{c}=$ fed according to requirements during the dry period, $-\mathrm{o}=$ overfed during the dry period. Closed circles depict second parity cows and open circles depict third parity cows.

were, however, similar to those obtained by analyses with all cows $(n=37)$ for week 2 only.

\subsubsection{Liver TAG}

Individual liver TAG contents are presented in Figure 3. The liver TAG contents of six cows are missing. Due to Foot and Mouth Disease regulations in The Netherlands (in the spring of 2001), the liver biopsies of these animals were not allowed to be transported from the farm to the laboratory. The liver TAG contents of the remainder of the animals were not affected by milk production level and/or feeding regimen. Parity affected liver TAG content significantly, with higher TAG levels in third parity cows $(P=0.004)$.

\subsubsection{Metabolites in the blood}

Plasma glucose, NEFA, BHB and urea concentrations from 2 weeks before until 3 weeks after parturition are presented in Figures 4, 5, 6 and 7. Pre-partum concentrations of glucose tended to be affected by the feeding regimen $(P=0.055)$, with relatively higher values in the overfed groups. Pre-partum concentrations of NEFA, BHB and urea were similar in all groups. Post- partum, mean plasma glucose and urea concentrations significantly decreased, and mean plasma NEFA and BHB concentrations significantly increased in all groups $(P<0.01)$. Post-partum concentrations of blood metabolites were similar in all groups. Post-partum glucose concentrations were significantly affected by parity, with relatively low glucose concentrations in third parity cows $(P=0.007)$.

\subsection{Host resistance}

\subsubsection{Severity of experimental E. coli mastitis}

Experimental intramammary infusions with 30-50 cfu E. coli resulted in clinical mastitis in all 36 cows. The cows showed a range of local and systemic signs of disease. Local signs consisted of swelling and increased firmness of the infused quarter and changes in the color and aspect of the milk. Systemic signs consisted of general depression, loss of appetite and elevated body temperatures. Severity of E. coli mastitis varied enormously between cows based both on clinical signs and on bacterial counts in the milk (expressed as peakcfu, AUC and BCT) and quarter milk production (RMP). The bacterial counts in 
HP-c

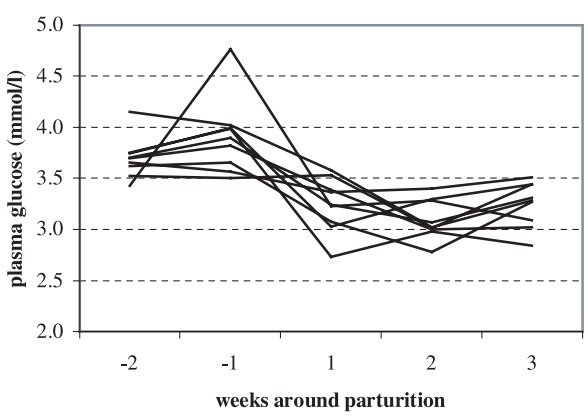

LP-c

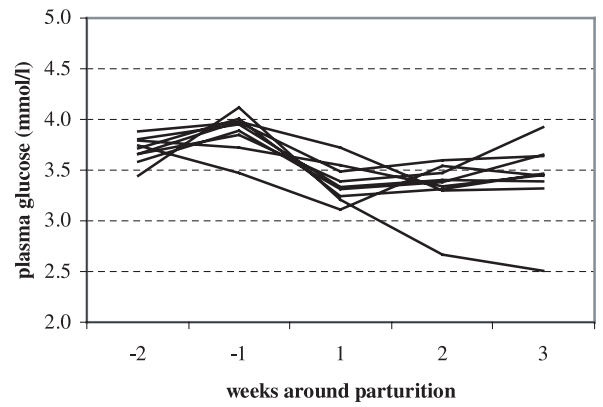

HP-o

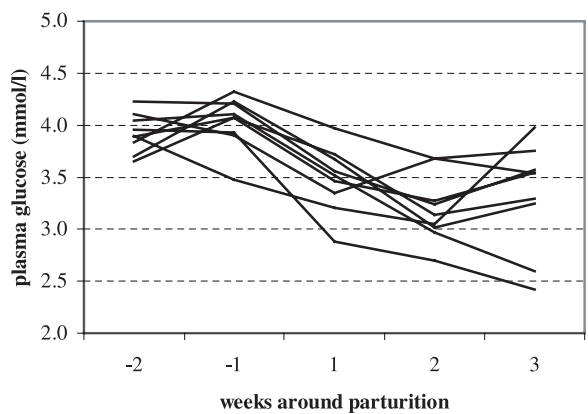

LP-o

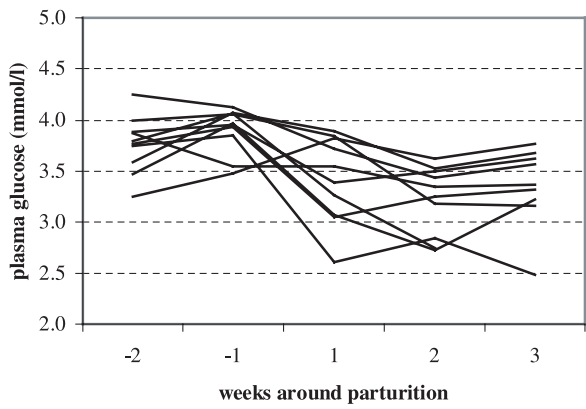

Figure 4. Individual weekly average plasma glucose concentrations in the four experimental groups from two weeks before until 3 weeks after parturition. $\mathrm{HP}=$ high producing, $\mathrm{LP}=$ low producing, $-\mathrm{c}=$ fed according to requirements during the dry period, $-\mathrm{o}=$ overfed during the dry period.

the milk of the cows with the lowest and highest AUC are presented in Figure 8a. The AUC of bacterial counts in milk for all individual cows are presented in Figure 8b. Different parameters for the severity of E. coli mastitis are summarized in Table II. Correlations between severity parameters ranged from 0.78 to $0.93(P<0.001)$. All cows eliminated the pathogen without therapeutic intervention, except for one cow from the HP-c group that needed treatment for secondary clinical ketosis. The severity of experimental E. coli mastitis was not affected by the production level or feeding regimen during the dry period for any of the measures (see $P$-values in Tab. II). Also, no effect of milk production level on the severity of experimental E. coli mastitis was seen when the animals' previous lactation FPCM or mean milk production in the pre-infusion week was included as a covariate.

\subsubsection{Associations with metabolic status}

Partial correlation coefficients between ${ }^{10} \log$ AUC and parameters of pre-infusion metabolic status are summarized in Table III. Correlation coefficients were low and not significant. No significant effects were seen when all pre-infusion metabolic parameters $\left(\mathrm{EB},{ }^{10} \log \mathrm{TAG}\right.$, glucose, NEFA, BHB and urea) were included as covariates in the general linear model. When BHB concentrations 
HP-c

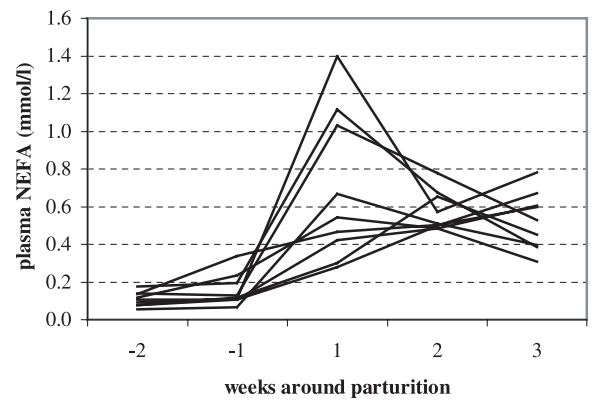

LP-c

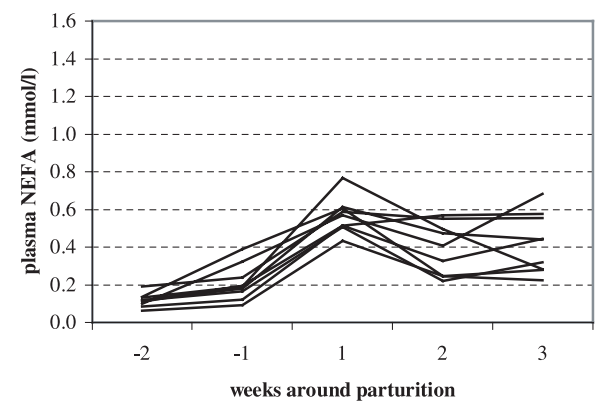

HP-o

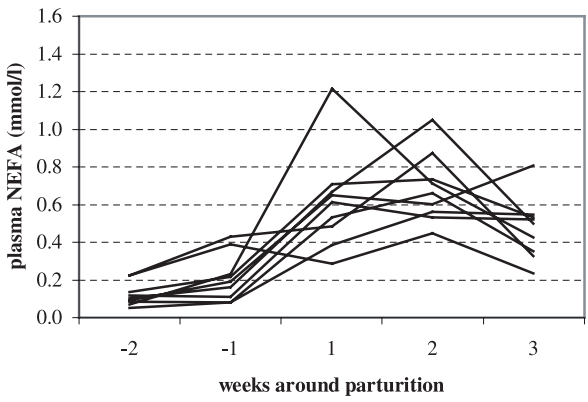

LP-o

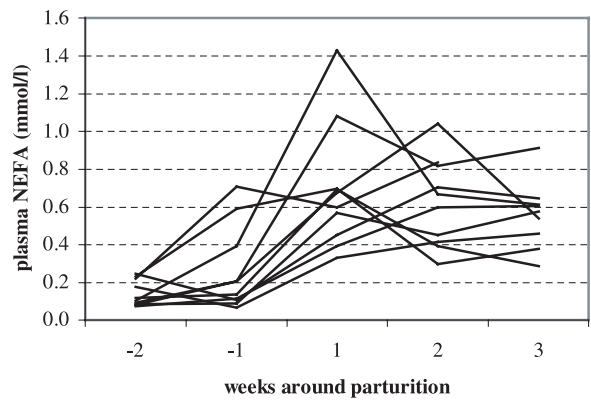

Figure 5. Individual weekly average plasma NEFA concentrations in the four experimental groups from two weeks before until 3 weeks after parturition. HP = high producing, LP = low producing, $-\mathrm{c}=$ fed according to requirements during the dry period, $-\mathrm{o}=$ overfed during the dry period.

were categorized (cut-off $1.4 \mathrm{mmol} / \mathrm{L}$; [13]), the severity of experimental E. coli mastitis was significantly affected by BHB concentrations, with higher ${ }^{10} \log$ AUC in cows within the higher category of BHB $\left(P=0.041 ; \mathrm{R}^{2}=0.12\right)$. Scatter plots of ${ }^{10} \log$ AUC with BHB concentrations as continuous and categorized values are presented in Figure $9 \mathrm{a}$ and $\mathrm{b}$, respectively.

\section{DISCUSSION}

The present experiment is the first to use a disease model to study the possible differences in host resistance between high and low producing dairy cows. The results suggest that milk production level per se does not negatively affect host resistance, as assessed by measuring the severity of experimentally induced $E$. coli mastitis. These findings agree with those of Detilleux et al. [4]. They measured host resistance parameters in a "steady state" situation, comparing cows from high and average genetic merit lines for milk production, and concluded that selection for high milk production does not compromise host resistance. Although the severity of experimental E. coli mastitis did not differ between the groups in the present study, large individual variation in severity was seen within groups. The same holds true for metabolic parameters like energy balance, liver TAG content and blood glucose, NEFA, BHB and urea concentrations. It has often been 
HP-c

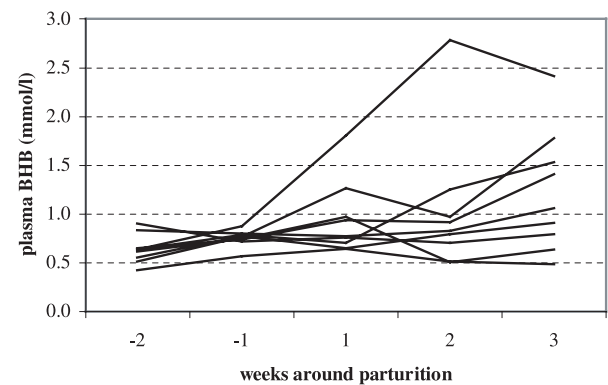

LP-c

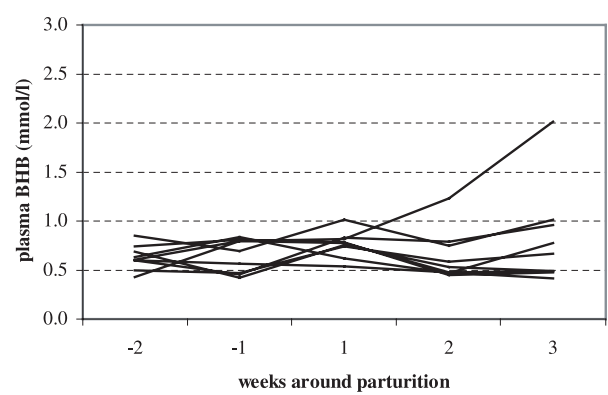

HP-o

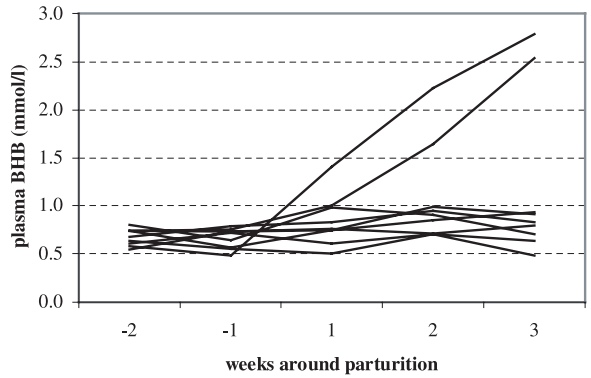

LP-o

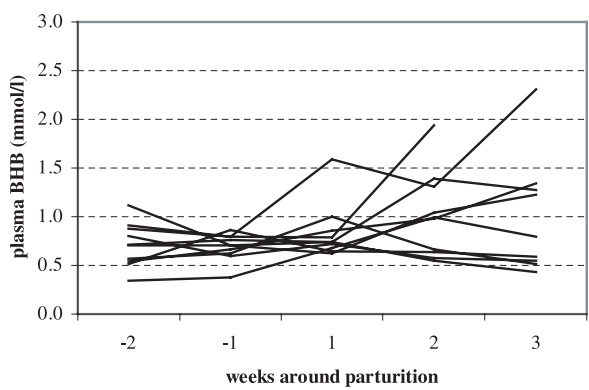

Figure 6. Individual weekly average plasma BHB concentrations in the four experimental groups from two weeks before until 3 weeks after parturition. $\mathrm{HP}=$ high producing, $\mathrm{LP}=$ low producing, $-\mathrm{c}=$ fed according to requirements during the dry period, $-\mathrm{o}=$ overfed during the dry period.

hypothesised that a negative energy balance (NEB) negatively affects host resistance. The evidence is, however, based mainly upon studies on ketosis, which is not synonymous with negative energy balance. A recent study by Perkins et al. [18] provided no evidence that NEB in itself affects host resistance. They found no relationship between energy balance and the outcome of intramammary endotoxin infusion, used as a mastitis model, in midlactation cows that were either or not feed-restricted. The present study clearly adds to the one by Perkins et al. [18] because of the use of early post-partum cows and a real pathogen in a mastitis model. The early post-partum energy balance was significantly affected by production level, and tended to be affected by feeding regimen, but was not associated with the severity of experimen- tal E. coli mastitis. From our studies too, it can be concluded that NEB per se does not have to be detrimental to the cow. Ketosis, however, has been described as a risk factor for mastitis in the field $[8,17]$. Kremer et al. showed that the course of experimental E. coli mastitis is relatively severe in ketonemic cows [13], and Van Werven et al. found a strong positive correlation between pre-infusion BHB concentrations and the severity of experimental E. coli mastitis $(r=0.78$ [25]). Ketone bodies, such as BHB, may exert a negative effect on the quality of polymorphonuclear leukocyte (PMN) functions, an important aspect of udder defence (see review by [22]). In the present study, no strong associations were found between pre-infusion blood metabolite concentrations and the severity of E. coli mastitis. Only BHB concentrations 
HP-c

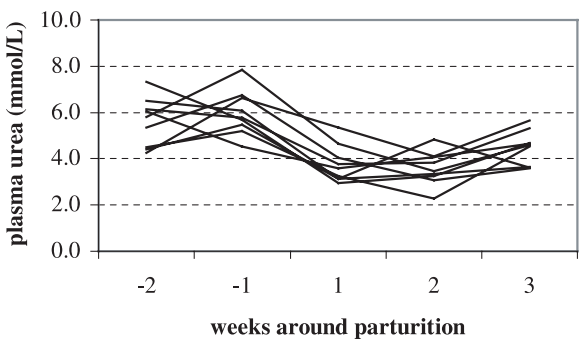

LP-c

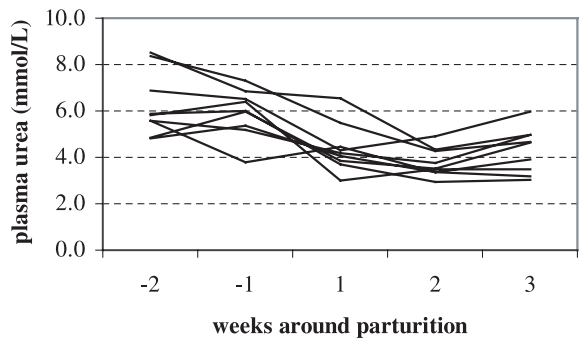

HP-o

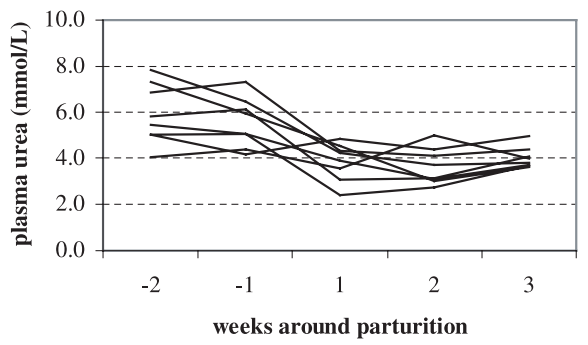

LP-o

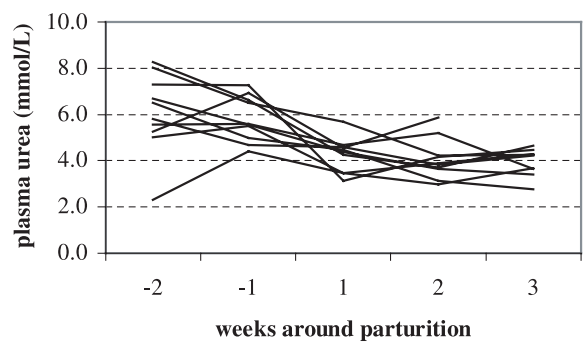

Figure 7. Individual weekly average plasma urea concentrations in the four experimental groups from two weeks before until 3 weeks after parturition. $\mathrm{HP}=$ high producing, $\mathrm{LP}=$ low producing, $-\mathrm{c}=$ fed according to requirements during the dry period, $-\mathrm{o}=$ overfed during the dry period.

above $1.4 \mathrm{mmol} / \mathrm{L}$ were linked to relatively severe experimental E. coli mastitis, although only $12 \%$ of the variation between cows was explained in this way. A difference with the earlier mentioned studies on ketosis and E. coli mastitis is that most cows in this study were able to keep their blood metabolite levels in the normal ranges. In the pre-infusion week, the cows had mean glucose concentrations above $2.5 \mathrm{mmol} / \mathrm{L}$, and mean BHB concentrations between 0.4 and $3.0 \mathrm{mmol} / \mathrm{L}$, i.e. concentrations that differ from those seen in the ketonemic cows in the study by Kremer et al., namely between 1.6 and $2.5 \mathrm{mmol} / \mathrm{L}$ and between 2.2 and $4.9 \mathrm{mmol} / \mathrm{L}$, respectively [13]. Also in the study by Van Werven et al., pre-infusion BHB concentrations were around $4 \mathrm{mmol} / \mathrm{L}$ in most cows [25]. It seems that blood metabolites affect host resistance only at levels that are associated with metabolic disease.
By means of overfeeding half of the cows in the dry period, it was expected that more animals in this study would have a poorer metabolic status post-partum and show, for example, BHB concentrations in the higher ranges. The increased pre-partum glucose concentrations in the overfed cows $(P<0.1)$ indicate that the feeding treatment was effective to some extent, but post-partum the differences between glucose concentrations disappeared and also other blood metabolites (NEFA, BHB, urea) did not differ between groups, indicating that the cows' coping abilities after calving were adequate. Parity significantly affected post-partum glucose concentrations and liver TAG content, with lower glucose and higher TAG content in third compared to second parity cows. This experiment was not, however, designed to study the differences between second and third parity cows, and thus does not allow 
(a)

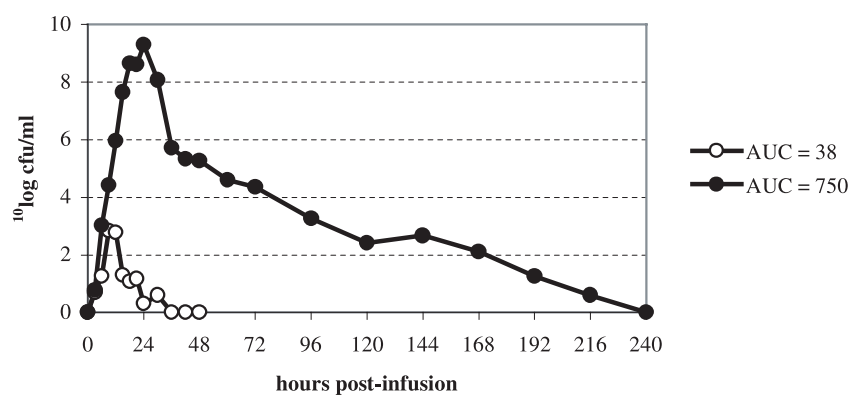

(b)

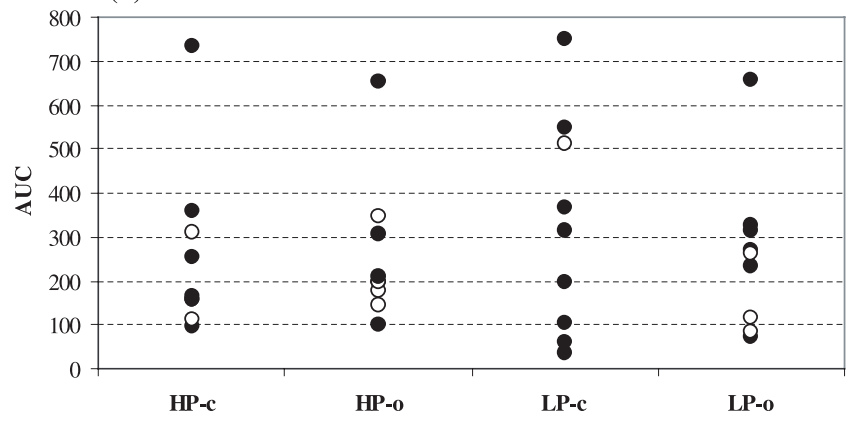

Figure 8. (a) Examples of individual bacterial counts in milk after infusion of 30-50 cfu E. coli in a rear quarter for the cows with the lowest and highest AUC. (b) Scatter plot of individual AUC $\left({ }^{10} \log \mathrm{cfu} / \mathrm{mL} \times \mathrm{h}\right)$ of bacterial counts in milk after infusion of 30-50 cfu E. coli in a rear quarter. $\mathrm{HP}=$ high producing, $\mathrm{LP}=$ low producing, $-\mathrm{c}=$ fed according to requirements during the dry period, $-\mathrm{o}=$ overfed during the dry period. Closed circles depict second parity cows and open circles depict third parity cows.

strong conclusions with regards to parity. In other studies, overfeeding during the dry period has caused serious metabolic disturbances such as fatty liver [20], but in these studies overfeeding during the dry period was usually followed by a short period of food deprivation from the onset of parturition [19]. It should be emphasized that in our experiments, overfeeding during the dry period was performed to model suboptimal management conditions in the field and not to induce a pathological state. As a result, the present regimen of overfeeding may have been only moderately effective in straining the animals.

A probably important difference between the feeding conditions in this study as com- pared to those in the field is that, because of experimental procedures, cows were housed in a tie-stall after calving, while in the field, most cows are moved as soon as possible from the calving pen to a free stall. In free stalls, access to food may be dependent on the animals' rank in the herd and the number of feeding places [15]. Limited feeding places can result in reduced uptake of food by especially low ranking animals, resembling a "feed restriction model" for some cows in a herd. For example, early post-partum cows housed in groups had higher NEFA concentrations than cows housed in individual box stalls [2]. Postpartum, the cows in this study were moved to a tie stall and were fed individually. 
Table II. Mean values ( \pm s.d.) of different parameters for the severity of $E$. coli mastitis. $P$-values for production and feeding effects on the severity of $E$. coli mastitis.

\begin{tabular}{lcccccc}
\hline & HP-c & HP-o & LP-c & LP-o & $\begin{array}{c}P \text {-value } \\
\text { production }\end{array}$ & $\begin{array}{c}P \text {-value } \\
\text { feeding }\end{array}$ \\
\hline Peak cfu $\left({ }^{10} \log \mathrm{cfu} / \mathrm{mL}\right)$ & $5.7 \pm 1.6$ & $5.8 \pm 1.4$ & $6.1 \pm 2.5$ & $5.8 \pm 1.8$ & 0.718 & 0.905 \\
AUC $\left({ }^{10} \log \mathrm{cfu} \times \mathrm{h}\right)$ & $262 \pm 199$ & $260 \pm 166$ & $322 \pm 246$ & $260 \pm 178$ & 0.930 & 0.999 \\
BCT $(\mathrm{h})$ & $129 \pm 62$ & $139 \pm 68$ & $141 \pm 68$ & $122 \pm 63$ & 0.649 & 0.871 \\
RMP $(\%)$ & $88 \pm 21$ & $84 \pm 29$ & $75 \pm 34$ & $91 \pm 23$ & 0.787 & 0.364 \\
\hline
\end{tabular}

Abbreviations: $\mathrm{AUC}=$ area under the curve for bacterial counts in milk in time, $\mathrm{BCT}=$ bacterial clearance time $(<1 \mathrm{cfu} / \mathrm{mL}), \mathrm{RMP}=$ residual milk production (\% of pre-infusion baseline in the three noninfused quarters); $\mathrm{HP}=$ high producing, $\mathrm{LP}=$ low producing, $-\mathrm{c}=$ fed according to requirements during the dry period, $-\mathrm{o}=$ overfed during the dry period.

Table III. Partial correlation coefficients and $P$-values of pre-infusion metabolic status and severity of E. coli mastitis expressed as ${ }^{10} \log$ AUC. Except for ${ }^{10} \log$ TAG, values for metabolic parameters were the mean of measurements in the week pre-infusion.

\begin{tabular}{lcc}
\hline${ }^{10} \log$ AUC & $\begin{array}{c}\text { Correlation } \\
\text { coefficient }\end{array}$ & $P$-value \\
\hline Energy balance & 0.06 & 0.72 \\
${ }^{10} \log$ TAG & -0.02 & 0.92 \\
Glucose & -0.11 & 0.54 \\
NEFA & -0.15 & 0.40 \\
BHB & 0.17 & 0.34 \\
Urea & -0.09 & 0.63 \\
\hline
\end{tabular}

Differences between cows in their ability to cope with the transition to a free stall were ruled out in this way. The results of this study suggest that detrimental effects of suboptimal dry period nutrition can be counteracted by excellent feeding conditions, e.g. unrestricted access to good quality food, after parturition.

Regardless of the effectiveness of the feeding regimen, this study clearly shows that milk production level per se does not affect host resistance as measured by the severity of experimental E. coli mastitis. This result seems to be in contrast with the results of epidemiological studies in which correlations have been found between milk production level and the incidence of mastitis $[6-8,17]$. The discrepancy between the results of epidemiological and experimental studies might be a pseudo-discrepancy. Gröhn et al. [7] pointed out that the higher incidence of mastitis found in epidemiological studies on commercial dairies could be the result of bias since diseased animals with low production are more likely to be culled than those with high production. This could explain the apparent greater risk of disease in high yielding cows. However, the higher incidence of mastitis found in epidemiological studies could also truly reflect the situation in the field. Experimental studies of mastitis differ from observational epidemiological studies in that the teat duct is surpassed, so only differences between cows at the level of the inflammatory response in the mammary gland (i.e. mammary epithelium, acute phase response, influx of PMN) are evaluated (for review see [12]). Thus the higher incidence of mastitis in high producing cows could be the consequence of differences in the quality of the teat duct. There is circumstantial evidence that the quality of the teat duct might be compromised in high producing animals. High milk production has been described as a risk factor for teat injury [8], and teat injury, in turn, as a risk factor for clinical mastitis $[8,17]$. In addition, selection for higher milk production has also 
(a)

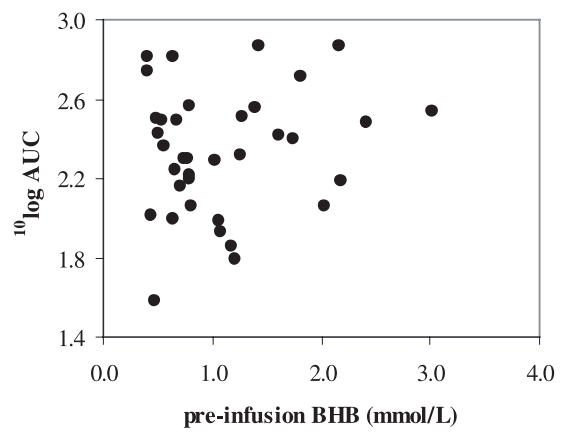

(b)

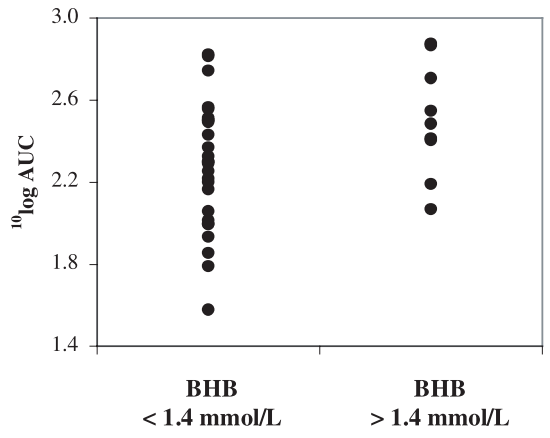

Figure 9. Scatter plots of ${ }^{10} \log$ AUC with preinfusion plasma BHB concentrations; (a) as continuous variable; (b) when categorized: $\mathrm{BHB}<1.4 \mathrm{mmol} / \mathrm{L}, \mathrm{BHB}>1.4 \mathrm{mmol} / \mathrm{L}$.

been a selection on a faster milk flow [11], which, together with increased mechanical pressure due to large volumes of milk, may cause increased leaking of milk in high producing cows [10]. The latter is associated with an increased risk of clinical mastitis [21]. The foregoing stresses the need for comparing the quality of the teat duct, as an important aspect of host resistance, between high and low producing cows. This could be achieved by using exposure of teat ends to an $E$. coli broth culture as a model, as it has been described by DeHart et al. [3].

In conclusion, milk production level did not affect host resistance in dairy cows, as measured by the severity of experimental intramammary infusion with $E$. coli in early lactation. Even in a situation that cows were metabolically stressed by overfeeding, high producers were as able as low producers to cope with the demands of milk production. The apparent increased susceptibility for mastitis of high producing cows in the field may be the result of factors such as decreased quality of the teat duct in high producing cows, or feeding management that result in a stronger impact on host resistance under field conditions as compared to the present experimental circumstances.

\section{ACKNOWLEDGEMENTS}

The investigations were in part supported by the Research Council for Earth and Life Sciences (ALW) with financial aid from The Netherlands Organization for Scientific Research (NWO) and the Dutch Ministry of Agriculture, Nature and Fisheries. The authors wish to thank Marjan Bralten-Benning for her contribution to the experimental set-up and the preparations for the experiment. The staff of "Hoorn" (research farm of the Institute for Animal Science and Health, Lelystad, The Netherlands), colleagues and students are greatly acknowledged for assistance with the experimental procedures. Arie Klop (Institute for Animal Science and Health, Lelystad, The Netherlands) is thanked for assistance with the aspects of the study that involved nutrition and Jan van de Broek (Centre for Biostatistics, Utrecht University) for assistance with the statistical analysis.

\section{REFERENCES}

[1] Barkema H.W., Schukken Y.H., Lam T.J., Beiboer M.L., Wilmink H., Benedictus G., Brand A., Incidence of clinical mastitis in dairy herds grouped in three categories by bulk milk somatic cell counts, J. Dairy Sci. 81 (1998) 411-419.

[2] Brand A., Noordhuizen J.P.T.M., Schukken Y.H., Herd Health and Production Management in Dairy Practice, Wageningen Pers., Wageningen, 1996.

[3] DeHart D.A., Natzke R.P., Oltenacu P.A., Effect of coliform challenge at milking time on new udder infections, J. Dairy Sci. 59 (1976) 1124-1130.

[4] Detilleux J.C., Kehrli M.E. Jr., Stabel J.R., Freeman A.E., Kelley D.H., Study of immunological dysfunction in periparturient Holstein cattle selected for high and average milk 
production, Vet. Immunol. Immunopathol. 44 (1995) 251-267.

[5] Erskine R.J., Eberhart R.J., Hutchinson L.J., Spencer S.B., Campbell M.A., Incidence and types of clinical mastitis in dairy herds with high and low somatic cell counts, J. Am. Vet. Med. Assoc. 192 (1988) 761-765.

[6] Fleischer P., Metzner M., Beyerbach M., Hoedemaker M., Klee W., The relationship between milk yield and the incidence of some diseases in dairy cows, J. Dairy Sci. 84 (2001) 2025-2035.

[7] Gröhn Y.T., Eicker S.W., Hertl J.A., The association between previous 305-day milk yield and disease in New York State dairy cows, J. Dairy Sci. 78 (1995) 1693-1702.

[8] Gröhn Y.T., Erb H.N., McCulloch C.E., Saloniemi H.S., Epidemiology of mammary gland disorders in multiparous Finnish Ayrshire Cows, Prev. Vet. Med. 8 (1990) 241252.

[9] Hogan J.S., Gonzalez R.N., Harmon R.J., Nickerson S.C., Oliver S.P., Pankey J.W., Smith K.L., Laboratory Handbook on Bovine Mastitis, National Mastitis Council, Inc., Madison, Wisconsin, 1999.

[10] Jones T.O., A review of teat factors in bovine E. coli mastitis, Vet. Rec. 118 (1986) 507509.

[11] Kelm S.C., Freeman A.E., NC-2 Technical Committee, Direct and correlated responses to selection for milk yield: results and conclusions of regional project $\mathrm{NC}-2$, "improvement of dairy cattle through breeding, with emphasis on selection", J. Dairy Sci. 83 (2000) 2721-2732.

[12] Kremer W.D., Noordhuizen-Stassen E.N., Lohuis J.A., Host defence and bovine coliform mastitis. Host defence mechanisms and characteristics of coliform bacteria in coliform mastitis in bovine: a review, Vet Q. 12 (1990) 103-113.

[13] Kremer W.D., Noordhuizen-Stassen E.N., Grommers F.J., Schukken Y.H., Heeringa R., Brand A., Burvenich C., Severity of experimental Escherichia coli mastitis in ketonemic and nonketonemic dairy cows, J. Dairy Sci. 76 (1993) 3428-3436.

[14] Lohuis J.A., Schukken Y.H., Verheijden J.H., Brand A., Van Miert A.S., Effect of severity of systemic signs during the acute phase of experimentally induced Escherichia coli mastitis on milk production losses, J. Dairy Sci. 73 (1990) 333-341.

[15] Metz J.H.M., Food competition in cattle, in: Baxter S.H., Baxter M.R., McCormack J.A.C. (Eds.), Farm animal housing and welfare, Martinus Nijhoff Publishers for CEC, The Hague, 1993.
[16] NRS, Jaarstatistieken 2001, Koninklijk Nederlands Rundvee Syndicaat, Arnhem, 2001.

[17] Oltenacu P.A., Ekesbo I., Epidemiological study of clinical mastitis in dairy cattle, Vet. Res. 25 (1994) 208-212.

[18] Perkins K.H., VandeHaar M.J., Burton J.L., Liesman J.S., Erskine R.J., Elsasser T.H., Clinical responses to intramammary endotoxin infusion in dairy cows subjected to feed restriction, J. Dairy Sci. 85 (2002) 17241731.

[19] Rukkwamsuk T., Wensing T., Geelen M.J., Effect of overfeeding during the dry period on regulation of adipose tissue metabolism in dairy cows during the periparturient period, J. Dairy Sci. 81 (1998) 2904-2911.

[20] Rukkwamsuk T., Kruip T.A., Wensing T., Relationship between overfeeding and overconditioning in the dry period and the problems of high producing dairy cows during the postparturient period, Vet. Q. 21 (1999) 71-77.

[21] Schukken Y.H., Grommers F.J., Van de Geer D., Erb H.N., Brand A., Risk factors for clinical mastitis in herds with a low bulk milk somatic cell count. 1. Data and risk factors for all cases, J. Dairy Sci. 73 (1990) 3463-3471.

[22] Suriyasathaporn W., Heuer C., NoordhuizenStassen E.N., Schukken Y.H., Hyperketonemia and the impairment of udder defense: a review, Vet. Res. 31 (2000) 397-412.

[23] Tamminga S., Van Straalen W.M., Subnel A.P.J., Meijer R.G.M., Steg A., Wever C.J.G., Blok M.C., The Dutch protein evaluation system: the DVE/OEB-system, Livest. Prod. Sci. 40 (1994) 139-155.

[24] Van den Top A.M., Wensing T., Geelen M.J., Wentink G.H., van't Klooster A.T., Beynen A.C., Time trends of plasma lipids and enzymes synthesizing hepatic triacylglycerol during postpartum development of fatty liver in dairy cows, J. Dairy Sci. 78 (1995) 22082220.

[25] Van Werven T., The role of leukocytes in bovine Escherichia coli mastitis, $\mathrm{PhD}$ thesis, Department of Farm Animal Health, Utrecht University, Utrecht, The Netherlands, 1999.

[26] Van Werven T., Noordhuizen-Stassen E.N., Daemen A.J., Schukken Y.H., Brand A., Burvenich C., Preinfection in vitro chemotaxis, phagocytosis, oxidative burst, and expression of CD11/CD18 receptors and their predictive capacity on the outcome of mastitis induced in dairy cows with Escherichia coli, J. Dairy Sci. 80 (1997) 67-74.

[27] Wentink G.H., Rutten V.P., Van den Ingh T.S., Hoek A., Muller K.E., Wensing T., Impaired specific immunoreactivity in cows with hepatic lipidosis, Vet. Immunol. Immunopathol. 56 (1997) 77-83. 